\title{
Making climate public: energy monitoring and smart grids as political participation
}

\author{
Hannah Knox
}

Abstract: This article presents the findings of ethnographic research in the UK with a network of engineers, activists, and citizens involved in developing smart energy monitoring systems and community smart grids. The paper explores how everyday uses of data, material evidence, and sensory information on material and thermodynamic processes that appear in such projects, are opening up new spaces for public participation in climate change politics. Here, familiar discursive and deliberative forms of democratic participation are supplemented by what I term material diagnostics - a practice of public participation that revolves around a collective effort to unpack and rethink infrastructures as sites of climate action. Building on these findings, the paper suggests that everyday digitally informed experiments with urban infrastructures have the potential to extend the kinds of political subjectivities and participatory politics that are possible, as governments seek to transition to a net-zero future.

Keywords: Public engagement, climate change, digital, data, anthropology, ethnography, participation, publics, community, energy.

Note on the author: Hannah Knox is Professor of Anthropology at University College London. Her research concerns the social and cultural life of infrastructures, with a particular interest in the way that technical infrastructures entail powerful cultural imaginaries with worldmaking effects. Her most recent work has been looking at the implications of environmental models and energy data in the remaking of cities. Her books include Roads: An Anthropology of Infrastructure and Expertise (with Penny Harvey, Cornell University Press, 2015); Ethnography for a Data-saturated World (with Dawn Nafus, Manchester University Press, 2015), and most recently Thinking like a Climate: Governing a City in Times of Environmental Change (Duke University Press, 2020). https://orcid.org/0000-0003-2294-0258 


\section{Introduction}

I have been following Tom ${ }^{1}$ on Twitter ever since I went to speak to him about his experiences of home energy retrofit, smart metering, and his ongoing attempts to reduce his carbon footprint through changes to his home and lifestyle. Today he has tweeted a picture of a new grey box propped up against his house, with the words 'and so it begins'. Although the heat pump is still to be wired and plumbed in, Tom is nonetheless proud to show off the new device, which will run alongside a solar battery further supporting his moves to energy efficiency through energy saving and microgeneration of electricity. The air source heat pump is just the latest in a series of energy-saving and energy-transforming technologies that have come to be a part of Tom's life over the past few years. Starting with a housing retrofit project which saw the complete overhaul of his home's insulation, Tom has, ever since, been a stalwart of energy technology innovation in the Northern English city in which he lives. An avid monitorer of his everyday energy use and prolific Twitter user, Tom has become a public advocate for climate-change oriented technology and voice-piece for the reflexive considerations that becoming rewired into a post-carbon electricity system might mean for people and the planet.

I first met Tom seven years earlier at a workshop that I attended as part of ongoing ethnographic research on urban climate change mitigation, where we were learning for the first time how to build our own DIY digital home energy monitors. The workshop was organised by an energy cooperative that was exploring new ways of helping homeowners understand their energy use, showing them how to share the data with the community, and exploring the impact of installing energy-saving technologies such as insulation and solar panels into their homes. Working at the intersection of climate change activism, urban climate change policymaking and digital technology development, the work of this cooperative was part of a broader community energy movement, which in recent years had begun to explore the role that smart meters, smart grids, and new forms of digital data might play in the transition to a zero-carbon future.

This paper takes as its focus the activities of this energy cooperative, its network of participants and its experiments with smart meters and smart grids, to explore how digital, data-inflected attempts at infrastructural transformation are creating a distinctive form of public participation in the problem of climate change. One of the challenges that climate change activists and policymakers often highlight as an obstacle that needs to be overcome in the transition to zero-carbon, is the issue of how to engage a broad public in both the challenge of climate change and in shaping the solutions to this often seemingly intractable and divisive problem. Attempts to

${ }^{1}$ All names and organisations have been given pseudonyms. 
constitute climate publics in the UK context have been varied. They extend from long-running practices of climate activism, which seek to use direct action, protest, and disruption to make visible to unaware publics the otherwise often invisible problem of climate breakdown; the publication of high-level independent policy reports alongside the publicisation of scientific findings in the mainstream press which seek to gain public interest through (arguably limited) media reporting; and more recently the creation of climate citizen assemblies - deliberative fora through which a wide range of views on climate change policy options can be debated, discussed, and discursively agreed upon. In each of these cases, the public is constituted as a discourse-community whereby either passively (as imagined community) or actively (as forum participants) people are framed as interlocutors in a debate about what should be done about climate change.

In this paper I seek to expand this sense of what public participation in climate change might look like. Building on research into the everyday work that goes into the making of low-carbon infrastructures, I point to the distinctive qualities of a 'climate public' that I found to be emerging in and around the community smart grid projects I researched. Whilst clearly a rather niche form of participation in climate change, I suggest that the nascent climate public which I explore in this paper, provides us with an opportunity to expand our sense of the spaces where public action on climate change is taking place, and to reimagine possible forms that it might take in the future.

\section{Infrastructural publics and climate change}

In recent years, the notion of the public as constituted primarily in a discursive and deliberative register has been challenged by various social science scholars who have drawn attention to the way people are situated as publics not only through language and discourse, but also through their relations to objects, materials, and technology (Anand 2011, Braun \& Whatmore 2011, Latour \& Weibel 2005). One key area of research in which this has been illustrated most clearly, is in work that has focused on people's engagement and entanglement in infrastructural systems (Anand et al. 2018, Boyer 2019, Harvey et al. 2017, Knox 2017). Recent work on environmental and urban infrastructures has shown that publics are not only constituted in relation to protest, media discourse, political deliberation, and democratic debate, but are also made and remade as collectives in and through mundane, everyday material and technical engagements with infrastructures of different kinds. When a new road is built, a windfarm proposed, or a housing estate planned, such projects draw out and materialise latent relationships between communities, officials, engineers, landscapes, chemicals, bodies, and livelihoods. Infrastructures are projects where, as de Boeck evocatively puts it, 'publics thicken' (De Boeck 2012). 
Recent work on climate urbanism has starkly illustrated how climate change is an infrastructural problem (Castán Broto et al. 2020). Reducing the carbon emissions of cities and creating resilience against future climatic effects in urban settings has been shown to be a project that will demand a fundamental transformation in the infrastructures through which cities and nations function. The buildings in which people live, the vehicles with which they move, the energy that powers homes and businesses, the food that people eat, and the goods that they buy are all being reconsidered in light of climate change. Each of these infrastructural transformations is a moment not only of technical change, but also a process in which people are being invited to engage as particular kinds of publics: whether the oppositional publics of public consultation, the passive consumers of smart city infrastructures, or the infrastructural publics of community energy projects.

This paper draws attention to a particular aspect of climate urbanism as infrastructure transformation, which appeared as central in my own research, namely the key role that digital technologies - in the form of smart meters and smart gridswere playing as components of these shifting urban infrastructures. Intriguingly, digital technology use in climate urbanism has been a relatively unexplored dimension of public engagement in infrastructural climate politics. A recent collection on the emerging concept of climate urbanism, for example, makes scant mention of digital practices, data analysis, or sensory technologies in an otherwise far-reaching and field-defining assessment of climate change in cities (Castán Broto et al. 2020). This is perhaps due to the deep-seated association of climate change with ecological or environmental relations, a framing which can sometimes reproduce a cultural separation between the domain of the natural environment on the one hand and activities of a digital techno-culture on the other (Knox forthcoming 2022, Latour 1993). And yet climate change is deeply inflected by digital technologies. The models through which climate change has been detected and made into an object of global policymaking are some of the largest and most sophisticated computational systems that exist in the world today: climate change is arguably the original big data problem (Edwards 2010). Future decisions about climate solutions are framed by Integrated Assessment Models (IAMS) - experimental computational models that perform cost-benefit and risk analyses by juxtaposing economic, energy, and climate data in future-world scenarios (Edwards 1999, Hastrup \& Skrydstrup 2012). Digital systems are also contributors to climate change, with emerging technologies like bitcoin and AI (artifical intelligence) demanding huge and increasing amounts of energy to function (Mora et al. 2018). At the same time, advanced digital systems of mapping, monitoring, and data processing are themselves being used to generate data visualisations, sonifications, and digital mapping of entities like rooftop solar potential, energy grids, environmental degradation, and migration patterns, which promise to operate as key devices for making the 
shape, feel, and affect of climate perceptible to experts and publics (Gabrys 2016, Houser 2014, Lippert 2015).

If infrastructures are sites where 'publics thicken', digital infrastructures have been shown to generate their own particular dynamics of public participation. A key insight of recent work on digital systems has been the way that such systems appear to be reconfiguring existing understandings of power and political relationships. On the one hand, the rise of global corporations, like Google, Facebook, ByteDance, and Amazon, appears to have shifted the primary site of governance and power from states to corporations who now control populations and their actions through their use of data mining, analytics, machine learning, and AI (Zuboff 2019). The way search engines and social media sites have shifted from tools designed to effect social connection to engines for the production of commercialisable data, has raised new questions about the 'public' nature of participation in platforms which use publicly generated data for private gain (Ruppert et al. 2017). On the other hand, digital technologies have in other contexts afforded a countercultural, libertarian or activist response to their potential for social and political organisation, generating the birth of things like the Free and Open Source movement (Coleman 2009, Kelty 2008), or the quantified-self movement (Nafus 2016) in which people have reinstated ideas about participation, democracy, free speech, and individualism through the medium of digital technologies, sensors, and software. Jeffrey Juris's work on digital activism, for example, has drawn attention to the way digital platforms have offered new ways of making global political networks, as well as raising their own challenges in terms of how to keep people engaged longer term in online activist networks (Juris 2008). Other digital infrastructures, such as the emergence of free and open source software (F/OSS), have been shown to be generative of what Chris Kelty has termed 'recursive publics': that is, forms of public participation in software generation that create open and public infrastructure whilst simultaneously positioning programmers as themselves constitutive of digital public sphere (Kelty 2008). From the top-down and from the bottom-up, digital platforms and data systems have been shown to be profoundly important sites for the negotiated rearticulation of what collective public life means, and the reconsideration of the appropriate or available forms of participation in this public life. If infrastructures have long been sites where publics are made and remade, digital infrastructures have introduced particular issues which need to be considered if we are to understand the kinds of public participation that contemporary grassroots climate change infrastructure projects are beginning to generate.

In what follows I draw on twelve months of ethnographic research with a community-based energy cooperative and their network of partners to explore how engagement with smart grids, smart meters, and data flows are framing the contours 
of public participation in climate politics. The research involved one day a week of participant observation with the energy cooperative with a particular focus on their involvement in a European Smart Grid Demonstrator Project. In addition, I participated in in several project meetings (virtual and face to face), conducted weekly informal interviews with staff of the energy cooperative, carried out seven recorded interviews with other members of the energy co-op, four recorded interviews with partner organisations participating in the EU project, and participated in broader activities related to municipal and community energy opportunities, including involvement in a collaborative research project into options for a municipal cooperative energy company involving grid operators, union representatives, and local policymakers. The research also involved archival research on the history of electricity infrastructure in the city where research was primarily conducted, consultation of reports and grey literature on UK and European community energy initiatives, and the organisation of a 'hackathon' involving policymakers, technical experts, and energy system employees, which addressed the question 'how can energy be made more equitable'.

Drawing on this research I explore how engagements with climate change, inflected through an attention to digital data emerging from the use of meters in community smart grid projects, are creating what I term 'infrastructural publics'. Confronted with information on material flows and energy relations, I suggest that people involved in such projects find themselves newly aware of their entanglement in infrastructural systems, with implications for ideas about political responsibility, agency, and the form that political action in the face of climate change might take.

\section{Rewiring community with smart grids and meters}

It is a rainy Thursday in September and a group of around thirty members of a European Community Smart Grid Demonstrator project are gathered outside the meeting room where the project feedback meeting is about to start. Some are slumped on sagging sofas, heads burrowed in laptops, others talking to colleagues with coffee mugs in hand, some seeking out a working projector or looking for a reliable Wi-Fi signal. Emailing, texting, preparing, testing, the group are getting ready to present to the project funders, their latest work to build, implement, and test a prototype community smart grid system.

NewGrid is a European project with partners in Belgium, Greece, Italy, Spain, and the UK. The partners at the meeting, including the project assessors from Brussels, have travelled from across Europe to the Old Mill Building at Northern Co-Housing, a housing cooperative on the edge of a town in the North of England, and one of the 
test sites for the NewGrid project. The meeting is ready, chairs lined up, and so we take our seats, ready to be welcomed by the Co-Housing group director who opens the meeting by explaining why an eco-housing cooperative might be interested in being involved in a technology project like this.

In the presentations that follow, the NewGrid project is explained. The aim of NewGrid is to demonstrate the feasibility of creating local, smart electricity grids that could potentially be used by cooperatives, local distribution service operators, and communities to generate, manage, and supply their own electricity within a particular locale, neighbourhood, or social network. To do this the project has brought together partners from across Europe with expertise in engineering, software development, and community engagement to build smart meters that will monitor electricity use; collate information into a central repository; and give different participants - citizens, grid operators, and communities - access to data that will enable them to better understand and manage their energy use. The aim of the project is to ultimately redesign, through the use of digital technologies, the socio-technical infrastructures that currently structure people's relationship with electricity. This is summarised on the project website in the following policy-oriented terms:

The main outcomes of the project are ICT tools that offer secure, stable and robust smart grids, allowing distribution service operators (DSOs) to mitigate management, replacement and maintenance costs of the electricity distribution grid, in presence of large share of distributed renewable energy resources.

The project proposes innovative business models for the new players in the electricity panorama, such as prosumers, aggregators and energy service companies, with the objective to facilitate the integration of next generation distributed renewable energy sources and active participation of the European citizens in the energy market (demand response schemas).

... The most innovative aspect of the project is the innovative and affordable smart low-cost advanced meter allowing more extended functionalities for consumers and prosumers in order to empower and protect European citizens.

Although this website text offers a rather abstracted and technical description of the project's aims, conversations with its members and the presentations at the workshop suggest that its technical ambitions were understood to be radical, environmentally driven, and deeply political. The five test sites for the project were all electricity cooperatives or non-profit organisations, who had long been working to explore how to effect a move away from fossil-fuelled capitalism and bring in a more ecologically and socially sustainable way of living with energy. This ranged from a project in Northern England which sought to reduce people's energy use through proper insulation and a greater sensitisation to the thermodynamics of houses; a project 
in Catalonia in Spain which was seeking to create incentives for citizens to invest in distributed energy generation by investing in a solar cooperative, and explorations of the possibility of keeping the economic benefits of renewable energy generation in local places through the development of peer-to-peer energy trading. What held these projects together was the ultimate aim to bring about a fundamental rethinking of the 20th-century model of how electricity has been generated, distributed, and supplied in Europe through the development of an alternative energy infrastructure.

\section{Reworking the electric public}

Northern Co-Housing, where the workshop was being held, was to be one of the test sites for the project. In the UK, testing the functioning of community electricity grid systems had proved quite difficult to achieve, constrained by technical infrastructures and regulatory systems that had been developed in the context of the creation of an analogue, fossil-fuel-powered national electricity grid in the early 20th century, and the later privatisation of the electricity industry in the 1990s (Nolden et al. 2020). One of the key aims of the creation of a national electricity grid in the late 1920s, had been to integrate an otherwise fragmented system of different voltages, appliances, and systems that had sprung up in local areas all over the country by standardising the distribution and supply of electricity with one national system (Hughes 1983, Luckin 1990). A key principle that this centralised grid had worked with was that electricity would be available to all citizens at nationally standardised cost, so that those who lived far from sites of electricity generation were not disadvantaged either in terms of reliability of supply or cost. We might say that in this way the national electricity grid, even before the wholesale nationalisation of the energy industry in the mid-20th century, had begun to usher in the idea of a national energy public (Bakke 2016, Hughes 1983, Latour \& Weibel 2005, Özden-Schilling 2015, Özden-Schilling 2016).

The more recent emergence of location-based, community, and municipal energy schemes, brought about as a result of the emergence of distributed and localised forms of electricity generation through solar panels, heat pumps, or community energy cooperatives was posing a potential transformation of this model of electricity as a public good for a national citizenship. This had raised concerns that sub-national energy generation and supply could have a divisive effect, potentially meaning communities or groups with greater access to energy resources would gain advantage over those with no access to energy generation. For this reason, regulatory restrictions were in place in England at the time of this research, that prevented communities from being able to sell locally generated electricity directly to local electricity users. Instead individuals and communities that generated electricity still had to give back any of the 
energy that they did not use themselves, to the national 'pool' of electricity, which, through market mechanisms, became once again distributed as a form of national resource through the national grid (Nolden et al. 2020).

Luckily for the NewGrid project, Northern Co-Housing was something of an anomaly in community energy terms. Unlike community energy groups that brought together individual households which were each, already, connected to the national grid, Northern Co-Housing was what was known as a 'behind the meter' cooperative. Northern Co-housing is made up of a group of forty-one houses, over thirty micro-businesses, and several communal areas, and was developed on a single site in the early 2000s. The whole site was connected to the national grid through just a single point, with the electricity measured through a single meter. This meant that what happened 'behind the meter' was invisible to the national grid, making it an ideal site for an experimental community smart grid project that could play around with the possibilities of reconfiguring demand and supply outside national regulatory infrastructures. For the community, what being behind the meter had meant in practical terms was that energy that was already being generated from solar panels and a hydroelectric generator and used on the site by households and small business units, and needed to be managed not by the usual billing structures of a commercial energy supply company but by one of the community members.

One effect of this arrangement was to constitute Northern Co-Housing not as a group of individual homeowners managing their own electricity consumption, but as a proto-collective that was experienced by Co-Housing members as existing in tension with the national energy system. Up until this point, the management of the site's electricity had fallen on the shoulders of Simon. It had been Simon's job to annually go around to each of the houses and business units on the site and read their electricity meter, writing the numbers down in a notebook and transferring them onto his computer. Simon had then had to work out the relationship between the electricity generated on site by the small hydroelectric generator and solar panels, the amount of electricity that everyone used, the amount of electricity used by shared spacesincluding the electric car club and a shared common room-and the amount being charged by the electricity company, in order to come up with an accurate bill for each household or business. Up until this point Simon had taken on the role of a kind of local grid controller - a 'job' for which he was not remunerated. The NewGrid project proposed to transform the community's ability to manage its energy use by digitising the monitoring and management of the site's electricity, replacing Simon with a centralised system of energy monitoring and display that could potentially be visible to anyone on the site. By adding smart meter extension units to sites of generation (the water mill and the club house where the solar panels were located) and also to the sites of consumption (namely the houses, business units, and an electric car charging point) 
and deploying a user-interface where this data could be analysed, the project sought to use smart meters and smart grids to give Northern Co-Housing residents a newfound control of their electricity use. However, as mentioned above, the effect of the putting in place local smart metering was not to individualise the management of electricity consumption but rather to increase the collective power of the site as an energy community. This was in direct contrast to the way that smart metering has often been understood as a technology neoliberal control.

\section{Socialising with smart meters}

The NewGrid's project to develop smart meters for the purposes of supporting community energy was being deployed in the UK in the context of a broader approach to smart metering that had been in place since the early 2000s. In 2012, the UK government had announced with some fanfare that by 2020 every household in the UK would have a smart meter in their home. The aim of smart metering in this national project was multiple: a pragmatic attempt to prevent the need for in-person meter readings by supply companies; a technical tool to link to the broader digitisation of the electricity grid to help grid operators identify faults on the system in real time and to resolve them remotely and quickly; and most crucially for our purposes, a way to give customers data on their energy use so that they could focus on how to use energy more efficiently.

Much of the marketing and enthusiasm for the national smart meter programme was promoted on this latter basis. Smart meters were primarily touted as a tool that would help people visualise their energy use. On the basis of this visualisation, it was argued that they would be able to make better choices about their individual energy use, saving money for themselves as consumers as well as indirectly contributing to nationally mandated targets for the reduction of energy for environmental reasons. Meters in the context of the national smart meter rollout functioned as a tool that addressed individual consumers, or households, asking them to enact themselves as part of a national public through a reconsideration of their own individual consumption habits within a system of inputs and outputs not unlike that of the smart city. Metering in general, and smart metering in particular, has thus been widely described as a tool of neoliberal governmentality, in that it seeks to ask individuals and households to self-discipline their energy use in response to data that is read as informational and transparent in its meaning (Coleman 2014, Schnitzler 2016).

Responses to this have been varied. Sociologists working in the field of energy practices have been deeply critical of a naive technological determinism which has often imbued projects that assume that data on energy use is transparent in its meaning, 
and predictable in terms of its social effects (Shove \& Walker 2014, Shove et al. 2014). Such studies have shown that energy practices are not behaviours that can or should be nudged with objective information to prompt rational attempts to save money or reduce carbon emissions but are deeply entangled with ideas about comfort, kinship, home, and responsibility (Hand et al. 2005, Shove et al. 2014).

An alternative, and less directly critical, approach to energy monitoring comes from those who have been interested in what the emergence of environmental data might tell us about broader shifting structures of social relations. Going beyond the idea that citizens are either units of behaviour that can be technically manipulated, or that they are social beings embedded in webs of meaning that directly contradict the ambitions of policymakers and technology developers, some more politically minded scholars have sought to address the broader philosophical and structural question of what kinds of persons and publics might be emerging as people begin to use sensory devices as a means of what Noortje Marres has termed a practice of 'material participation' (Marres 2015).

This work has suggested that what emerges when people begin to engage with and use environmental data in their everyday lives is less a straightforward nudge towards pro-environmental behaviours, than a way of being in which people's sense of themselves as persons or citizens is iteratively and constantly shaped through their sense of themselves in relation to material flows (Naus et al. 2015, Strengers 2012). For Marres, this takes the form of a new kind of publicness which is entangled with people's newfound sense of their domestic lives as a facet of a broader environmental ecumene that is sustained and experienced through blogs, photo sharing, and public performance (Marres 2011, 2015) . For Jennifer Gabrys, the environmental subjectivity that comes from an engagement with environmental data is not just a new way of performing the self but is also entangled with new modes of governmentality that seek to survey and control emerging publics through disciplinary techniques of monitoring and automation (Gabrys 2014). For Gabrys, this creates an experience of urban citizenship as constituted through a governmental practice that she terms 'environmentality'. Here the individual is no longer constituted as a citizen through their incorporation into a broader public as a site of discourse and practice, but is now constituted as a node or data point within a terrain of data-mapped relations. This is demonstrated in Gabrys' work through an attention to air quality monitoring, in which the driver of a car, a factory, or a household that burns coal, become visible into the urban data dashboard as equivalent units that both contribute to and shape the 'problem space' of urban air quality (Lury 2021, Mattern 2015). Akin to analyses of big data analytics as a mode of platform governance or surveillance capitalism, environmental data in this framing highlight the way that digital sensing has the capacity to enact a top-down, data-driven refiguration of social life. 
In the case of the smart metering and smart grid projects that I followed in my research, the implications of new forms of environmental data for people's sense of themselves and their place in the world appeared less as a form of imposed 'environmentality' than, what I have come to term elsewhere, a more bottom-up practice of material or infrastructural diagnostics (Knox 2020). To participate, through attention to data of different kinds, in a material diagnostics was in this case not the transformation of the urban citizen into the subject/object of environmentality-nodes in a system of information exchange. In contrast, a digitally inflected material diagnostics seemed to actually open up a renewed space of participation and deliberation, inviting people to engage in fresh ways with questions about the relationship between public and private life, which now revolved around the relational properties of materials as they became revealed anew in the practice of everyday, bottom-up energy monitoring. To explore this further, let us return to some of the people who I met in the research, who were involved at a day-to-day level in monitoring and measuring their energy.

\section{Material diagnostics}

Some months after the initial project meeting, I returned to Northern Co-Housing for a participatory workshop that sought to explore with the housing group how they might be able to make the use of the data that were coming from the smart meters. Matthew, from the NewGrid project, began the workshop by showing a slide displaying an anonymised feed of electricity data from one of the smart meters that had been installed on the site in one of the Co-Housing resident's houses. He quickly talked through the graph of energy data, before opening up the floor for a broader discussion with members of the Co-Housing community about how they would like to monitor their energy and use the data.

Although not described in much detail, the graph displaying energy data was the trigger for many questions from the group. One of the members started the discussion by asking about the baseload represented on the graph, and whether there was an app that could help them disaggregate the data so as to differentiate between the baseload of electricity that stretched out at the bottom of the graph, and the fluctuations of electricity skipping along above this. Matthew's response was that the best thing to do would be to just turn appliances on and off and make a note of what happens on the feed in real time.

Discussion then moved on to recall previous attempts to analyse the data onsite prior to the installation of the smart meters. Here stories of energy monitoring discrepancies began to be told: like the time when the aggregated data on the energy being used by the business unit tenants did not add up to the whole building's calculated 
energy use. This prompted an interrogation to try to work out which of the businesses this extra energy use was coming from, why it was not registering in the data, whether the meters were installed properly, or whether there were collectively owned objects which used energy but that were not being taken into account. In spite of these problems, the transformative potential of data was also expressed, with several participants coming up with ideas about projects and activities that new streams of energy data could enable. One participant told a story, for example, of another co-housing site where they had set up an alert with the sound of a dog barking broadcast over a Tannoy to alert everyone that the grid was at low capacity and they could put their appliances on. Another asked whether a traffic light system could be installed in their shared laundry room to indicate whether their renewable sources were generating electricity and if it was therefore a good time to put the washing machine on.

What emerged from this discussion was the way that engagement with even rather mundane digital data streams on energy use prompted an attention to matter and its relations through what I am calling here material diagnostics (Knox 2020, 2021). Material diagnostics was importantly not just an engagement with data itself, but a practice that took data as a prompt to interrogate a much wider set of material and social relationships in which people came to realise that they were embedded.

This sensibility came up in conversations with many other people I spoke to during the course of my research. As well as following the NewGrid project, I also interviewed and participated in workshops and events with a wider group of people who were members of one of the energy cooperatives that was part of NewGrid project. They too expressed a similar relationship to energy data as that which was articulated by the Northern Co-Housing workshop participants, with energy data opening up a diagnostic relationship with ready-to-hand materials, interpersonal social relations, and broader infrastructures of energy supply, distribution, and generation.

When I went to interview Tom, with whom this paper opened, he spent a lot of time explaining to me the variety of relationships to which he had become sensitised as he read his energy data. Tom's sensibility to his home and its functioning that emerged through his close engagement with energy data had initially been prompted by attempts to make his house more environmentally friendly. Over time he had worked hard to combine data from meters and sensors with information on prevailing weather conditions described through data from the Met Office, the carbon dioxide emissions associated with his travel, and how he and his family heated and lit his home. Monitoring these material properties and practices amplified Tom's awareness of many aspects of the material and ecological infrastructures that held his life in place, from his home, to where he worked, to what he ate and where he travelled. It prompted him to reflect on his ongoing use of a petrol car and partly influenced his decision to buy an electric bike and eventually an electric car. 
As Tom had developed and deepened a sensibility to energy, pollution, and thermodynamics through these ongoing activities, these had caused him to go beyond a consideration of his direct material circumstances of his house to attend to other kinds of relations. These interrogations were not always intentional, with data and new energy-saving technologies often causing Tom to think about aspects of his life in ways that were quite unanticipated. One example of this was the diagnostic effects that unfolded when, after years of energy monitoring, and after installing solar panels on his house, Tom and his family decided to buy an electric car. Because it needed to be charged up through the home, and because they were trying to be environmentally conscious, the electric car needed to be parked close to the house either at times of lowest grid intensity, or when Tom's solar panels were producing electricity, so as to make the charging as ecologically effective as possible. To reach the charging point, however, the car had to be parked in the back alley that ran along the rear of the house. Tom told me that this was awkward, as it would mean asking neighbours to move their cars so that he could put his car onto charge:

People can park at both ends and block us out-they can block us in as well. Normally, you've just got to knock on their door and say 'you're blocking me in', but if it's just 'you're blocking the street I want to plug my car in' I don't feel like, really I should go and bother them for that.

Asking people to move their cars to access a street in order to charge an electric vehicle at times dictated by data on environment properties and relations felt different to asking people to move their cars so as to get one's own vehicle out to drive it. The reason for why this was the case was left hanging, with Tom simply saying 'you know what I mean?' And I felt like I did. In the context of the rest of the conversation it did seem like it might be presumptuous to knock on a neighbour's door and interrupt them for what might have been seen as an indulgent, selfish, or inflexible demand to plug a vehicle in at an otherwise seemingly idiosyncratic time of day. Material diagnostics in this case, was not only about tracing out the implications or possibilities brought to the fore by data, but also attending to the implications of the decisions that were informed by the informational flows that energy data produced: implications which pitted being an infrastructural public against being, in this case, a good neighbour.

This issue of the unfolding, and ongoing process of sensing, analysing, interpreting, and then trying to act appropriately was explained to me once again when I went to speak to another interviewee. Eric was a climate scientist by profession. He had become particularly involved in energy monitoring as part of an eco-renovation project to transform an old vicarage that he and his wife had bought. He had told me how he had been interested from the outset in monitoring his data. He was very comfortable with using spreadsheets to calculate material properties and told me he used 
spreadsheets extensively in the project. Nonetheless, as Eric became more sensitised to questions of energy and materials, he found himself moving away from spreadsheets of energy data, and incorporating a more expansive experimental and materially explorative approach to his renovation project.

One of the surprising effects of attending, first through data, and then through materials, to the complex and unfolding social-material world of energy transformation, was that it opened up the possibility that existing ways of doing things could be done otherwise. As Eric and I discussed the process of retrofitting the old vicarage, he started to tell me how a data-driven attention to the energetic properties of his new home prompted a material inventiveness and creativity that he did not initially anticipate.

One story he told me was the conundrum they were faced with when they wanted to insulate an arched window. The builder had never encountered anyone who wanted to insulate an arch before, and so Eric set about working out a way to go about the task. He first consulted an architect friend who was helping with the retrofit project, who sensitised him to the basic language he needed to understand what a window arch was in architectural terms (the wall as 'reveal', the 'kiss' where the wall and ceiling meet). Analysing the arch 'reveal', they realised that the archway was not straight but was actually a 'section through a cone' and so, finding an online cone calculator Eric found himself able to work out a way of calculating the area that needed to be insulated and the shape the insulation would need to be:

So I put the measurements in for the size of the windows. And then built myself a giant protractor-on the floor. So I used a bit of string on a chair leg and a bit of wallpaper roll. And then drew these conical sets. And then put them over this flexible insulating blanket. And then we cut out the right shape. And then Dylan [the builder] thought of a way of using some old polythene pipe around the inside as a frame. And we screwed and stapled onto the pipe. So that's how we ended up with the curved insulation.

Having taken two days off work to be with the builder and to make this intervention, Eric reflected 'It was fun, and I'd like to think he was my friend now and not just someone I've given tens of thousands of pounds to over nine months work!'

In this case the experimentation led to a renewed relationship with his builder, built out of an explorative and environmentally attuned relationship with materials. It also meant a new-found understanding of buildings - from the terms used to describe them, to the history of insulation techniques, to the way that builders often seemed to work not through concrete calculations but through more of a 'rule of thumb' approach. Other stories that Eric and Tom told me opened up detailed analyses of the functioning of the solar panel industry, government regulations on feed-in tariffs, an analysis of the relationship that they had historically had with their energy company, 
how such companies provided data (or not), and the kinds of possible relationships that they might be able to forge in the future with alternative energy generators, suppliers, and technologies.

It could be argued that the material diagnostics that characterised people's engagement with digital and data-mediated environmental processes are simply an extension to the kind of diagnostics that has always been a part of working with ready-to-hand materials and their properties (Ingold 2002). Nonetheless, I suggest that the use of data - on electricity, thermal properties, or cost - not only invited people to engage with materials and their properties, but invited those installing energy-saving technologies or smart meters, or retrofitting their houses, to locate themselves and their material relations within a wider social, infrastructural, and environmental set of relationships that was constantly brought back into view by environmental data. In all the interviews I conducted, people moved in and out, from data analysis on specific issues of energy usage to a broader form of questioning about the way that energy positioned them within existing social and energetic infrastructures, and then back into energy data. It is this experience of being made aware of being part of a complex, entangled, infrastructural systems of relations-which often conflicted with other forms of conducting social life, and over which people frequently realised they had relatively little control - that I refer to as the experience of being part of an 'infrastructural public'.

This brings me to a final point about these practices of material diagnostics that become revealed through an attention to digital environmentalism: that is, the way that these practices become themselves made public through the use of digital platforms and networks. In the case of all of the people and projects I have discussed, the actions taken to reduce energy, be more environmentally friendly, change housing methods, insulate buildings, or attend to thermodynamics were oriented not only to the direct benefits they would generate for individuals, or even the intimate interpersonal relations they established or transformed, but also to a wider sense of enacting a way of being part of a nascent climate public that might collectively start to act upon these infrastructural systems.

Recall the opening example of Tom's Twitter feed. Tom's material diagnostics had moved over time from being a personal project of energy monitoring to a public demonstration of what becomes possible when environmental monitoring becomes part of one's way of being in the world. Even before installing smart metering and monitoring in his home, Tom had started to help other people who belonged to the same energy cooperative learn how to read their energy meters, collate the information in spreadsheets, and begin to discern patterns over time. When Eric told me about another part of the retrofit process, a heat-recovery unit for their hot water pipe that was feeding his shower and 'our only bit of eco-bling'- he told me he was still a bit 
sceptical about the ecological benefits of this expensive piece of equipment but that he would do it again in his own home because 'it's an interesting one to talk about because it makes people think about hot water'. Both Eric and Tom had taken albums-worth of photographs of their retrofit process to share with others who would be interested in doing the same thing. Another couple who I went to speak to who were also thinking of installing a smart meter in their home after having undergone a major renovation to make it more energy efficient, told me of their desire to build a political movement around what they had learnt through their own attempts at saving energy. They were overtly sceptical of the government's smart meter programme, which they saw as a corporate scam, but at the same time, they showed me a large A4 notebook in which they had carefully monitored their own energy use over the past several years, juxtaposing energy data with other forms of environmental observation, and told me of how they wished to inculcate a similar sensibility in others by building a network of activists through email and conversations like the one we were having.

Returning to the NewGrid and to Northern Co-Housing's involvement in this project, both of these were also framed in terms of their orientation towards a refigured public that might unfold through the detail of engagement with energy infrastructure and its digital possibilities. NewGrid framed itself as a demonstrator of what could be possible when urban and community grids were redesigned using digital systems. What emerged was the prospect that digitised energy systems might reconstitute the scale and scope of what an energy collective could look like. This might take the form of peer-to-peer energy trading that would create new collectives out of networks of citizens repositioned as energy generators, or alternatively the invention of place-based community power stations that would become energy suppliers to local areas. The idea of the community power station was a topic that several Northern Co-Housing residents were fascinated by, hoping that eventually the connective and informational possibilities of a functioning smart grid might enable them to forge social, economic, and energetic links beyond their community to a local village, allowing them to share their locally produced electricity with others that they cared about and with whom they wished to forge stronger bonds. As my fieldwork with the NewGrid project drew to a close, its participants were continuing to interrogate digitally enabled alternatives to energy generation. These were now opening up from discussions of local communities as sites of energy generation, to further talk of municipal energy companies, regional power networks, and cooperatively owned place-based energy service companies (ESCOs). These discussions and experiments, grounded in a practice of digitally inflected material diagnostics, entailed nothing less than the working out and bringing into being, through the bottom-up design of technical systems, of a vision of a new kind of social contract between people, energy, and environment. 


\section{Conclusion}

In his historical study of the emergence of electric light in 19th-century Europe, Wolfgang Schivelbusch describes the effects of the incursion of gas pipes and electrical cabling into people's homes (Schivelbusch 1988). As private companies laid infrastructure from the street into people's living rooms and bedrooms, this transgressed a carefully policed bourgeois boundary between the realm of public life, and the private domestic interior.

The unease about gas and electric light in the nineteenth century can now take its place in a larger setting. Like daylight, this sort of light had an outside source. Ostensibly burning in the middle of the room in the lamp, its real origin was in the gas-works or in the central electric supply station, that is, in big industry, from which the bourgeois psyche tried to separate itself as it did from the public sphere. Just as the public sphere gained access to the home with daylight, so big industry forced its way in with the light of the gas flame and the electric bulb. (Schivelbusch 1988)

In a similar way, smart meters and smart grids now bring data feeds, Wi-Fi connections, digital visualisation, and smart appliances into the domestic space of the home. However, if 19th-century families struggled with the incursion of the public realm into private domestic space, I have suggested that the sensitisation effected by environmental data, at least among my environmentally attuned interlocutors, seemed to point to an embrace of the new-found experience of 'being infrastructural'. Monitoring and connecting had the effect of constituting these people as part of an infrastructural public, to such an extent that people would actively turn their homes into an object of public deliberation. This making infrastructural of homes and houses through insulation, grids and smart meters, and batteries, not only generated the grounds for the emergence of an infrastructural climate public, but also reinvigorated conversations about the place that collectivities might play in this public sphere of material participation and the appropriate scale at which they might most effectively work.

The activities that I have focused on in this paper were the practices of a rather niche group of individuals - technically competent, financially secure, environmentally concerned, and politically left-leaning. However, the finding that engaging in infrastructure through digital technologies has the potential to stimulate participation in climate change discourse raises the question of what kinds of climate publics might become possible if infrastructure planning and ownership were returned to individuals and communities.

We have seen in the cases presented here, how data on material properties, particularly when collated and revisualised through smart metering and smart grid 
systems, reframed the conditions of possibility through which action in the world could be pursued. What seemed odd, or impossible, or strange without a sensibility to thermodynamics and energy infrastructure afforded by meters and grids - insulating an arch, recovering heat from a shower, or thinking about energy in extensive terms that went beyond one's own energy bills and the four walls of one's home-now seemed possible, and indeed logical. Enthused by this opening up of an alternative way of thinking about and engaging with urban environment recast in terms of energy, digital environmentalism came to re-pose the question of public participation reframed in terms of energy relations.

In this paper I have sought to unravel the idiosyncrasies of actually existing engagements with smart grids and smart meters, with a view to showing how engagement with contemporary infrastructure has the potential to play a crucial, if under-appreciated, role in urban climate politics and the making of infrastructural publics. In direct opposition to the hyperbole and techno-modernism of smart city proposals that see urban life in terms of computational operating systems, with people and resources conceived as inputs and outputs that need to be manipulated and managed, this paper has shed light on how people who have access to the design and ownership of infrastructure, are using digital systems in their everyday lives as they seek to live with and through the challenges of climate change and situate themselves as climate publics. I have suggested that this form of digital environmentalism is a practice that augments material sensibilities, with the effect of creating ways of reinhabiting the city through the publicisation of hidden or privatised infrastructures and practices of diagnosis, and a querying that can support intervention into, and transformation of, such infrastructures.

What we find, in the everyday use of smart meters and grids, then, are the seeds of a climate public that is both broader than the niche of environmental activism but more specific than the notion of a general public that must be engaged to 'do something' about climate change. Whilst informed by environmental concerns, which were often the trigger for involvement in these practices in the first place, technology use among my interlocutors invited a form of engagement with material infrastructures, which simultaneously revealed and diagnosed the arcane and sometimes bizarre energy systems that existed behind walls, under floorboards, and beyond the plugs. Data traces opened up questions about relationships that did not always conform to existing or established boundaries: between the family and the individual, the private and the public, community and the state. It led to a tracing and a questioning of fundamental questions of the possibilities that might exist for participating in public life, recast as life lived in and through infrastructure.

Whilst this paper has focused on people's use of smart meters and community grids to reconfigure and understanding of energy systems, there are signs that similar 
dynamics might be observed with other kinds of digital environmental practices. Air-quality monitoring has similarly led to activities that have sought to remap urban spaces in terms of pollution hotspots, creating public campaigns and creating an impetus for redesigning streets for people rather than cars. Urban litter picking collectives find themselves mapping litter collection, sharing successes on Facebook, and tagging fly-tipping on council run websites, creating new relations of care with urban landscape. Similarly the monitoring of chemical residues in towns and regions afflicted with industrial pollution, have led to the visualisation of the effects of such residues on bodies, food, and wildlife, engendering an activism which deploys bottom-up citizen-produced data against corporate power. And indeed even these distinctions are possibly too rigid. Beyond the walls of government departments or the carefully policed boundaries of academic disciplines, these various forms of digital environmentalism in the city blur the boundaries between energy, biodiversity, waste, transportation, food, or heat as sites of environmental transformation. Too often digital sustainability takes a top-down approach to how digital systems could be used as technologies of surveillance, management, and control in ways that fail to recognise the creative, disruptive, and transformative ways they are already being incorporated into urban life. In drawing attention to everyday digital environmentalism, this paper has sought to show, through a more grounded, ethnographic understanding of urban climate change, new possibilities that are emerging for rethinking the future of cities and citizenship, as sites of entangled social and political and ecological relations.

\section{References}

Anand, N. (2011), 'PRESSURE: The PoliTechnics of Water Supply in Mumbai', Cultural Anthropology, 26(4): 542-64. https://doi.org/10.1111/j.1548-1360.2011.01111.x

Anand, N., Gupta, A. \& Appel, H. (2018), The Promise of Infrastructure (Durham, NC, Duke University Press). https://doi.org/10.1215/9781478002031

Bakke, G.A. (2016), The Grid: The Fraying Wires Between Americans and Our Energy Future (New York, Bloomsbury USA).

Boyer, D. (2019), Energopolitics: Wind and Power in the Anthropocene (Durham, NC, Duke University Press). https://doi.org/10.2307/j.ctv12102bw

Braun, B. \& Whatmore, S. (2011), Political Matter: Technoscience, Democracy, and Public Life (Minneapolis, MN, University of Minnesota Press).

Castán Broto, V., Robin, E. \& While, A. (2020), Climate Urbanism: Towards a Critical Research Agenda (Cham, Springer International). https://doi.org/10.1007/978-3-030-53386-1

Coleman, E. G. (2009), 'Code is Speech: Legal Tinkering, Expertise, and Protest among Free and Open Source Software Developers', Cultural Anthropology, 24(3): 420-54. https://doi.org/10.1111/j.1548-1360.2009.01036.x

Coleman, L. (2014), 'Infrastructure and Interpretation: Meters, Dams, and State Imagination in Scotland and India', American Ethnologist, 41(3): 457-72. https://doi.org/10.1111/amet.12084 
De Boeck, F. (2012), 'Infrastructure: Commentary from Filip De Boeck', Cultural Anthropology Online Curated Collections.

Edwards, P.N. (1999), 'Global Climate Science, Uncertainty and Politics: Data-laden models, Modelladen Data', Science as Culture, 8(4): 437-72. https://doi.org/10.1080/09505439909526558

Edwards, P.N. (2010), A Vast Machine: Computer Models, Climate Data, and the Politics of Global Warming (Cambridge, MA, MIT Press).

Gabrys, J. (2014), 'Programming Environments: Environmentality and Citizen Sensing in the Smart City', Environment and Planning D, 32(1): 30-48. https://doi.org/10.1068/d16812

Gabrys, J. (2016), Program Earth: Environmental Sensing Technology and the Making of a Computational Planet (Minneapolis, MN, University of Minnesota Press). https://doi.org/10.5749/minnesota/9780816693122.001.0001

Hand, M., Shove, E. \& Southerton, D. (2005), 'Explaining Showering: A Discussion of the Material, Conventional, and Temporal Dimensions of Practice', Sociological Research Online, 10(2): 1-13. https://doi.org/10.5153/sro.1100

Harvey, P., Bruun Jensen, C. \& Morita, A. (2017), Infrastructures and Social Complexity: A Companion (London, Routledge). https://doi.org/10.4324/9781315622880

Hastrup, K. \& Skrydstrup, M. (2012), The Social Life of Climate Change Models: Anticipating Nature (Hoboken, NJ, Taylor and Francis). https://doi.org/10.4324/9780203093870

Houser, H. (2014), 'The Aesthetics of Environmental Visualizations: More Than Information Ecstasy?', Public Culture, 26(2) (73): 319-37. https://doi.org/10.1215/08992363-2392084

Hughes, T.P. (1983), Networks of Power: Electrification in Western Society, 1880-1930 (Baltimore, MD, Johns Hopkins University Press).

Ingold, T. (2002), The Perception of the Environment: Essays on Livelihood, Dwelling \& Skill (Abingdon, Taylor \& Francis).

Juris, J.S. (2008), Networking Futures: The Movements Against Corporate Globalization (Durham, NC, Duke University Press). https://doi.org/10.2307/j.ctv11sn2g6

Kelty, C.M. (2008), Two Bits: The Cultural Significance of Free Software (Durham, NC, Duke University Press). https://doi.org/10.2307/j.ctv1198vx9

Knox, H. (2017), 'Affective Infrastructures and the Political Imagination', Public Culture, 29(2): 363-84. https://doi.org/10.1215/08992363-3749105

Knox, H. (2020), Thinking Like a Climate: Governing a City in Times of Environmental Change (Durham, NC, Duke University Press). https://doi.org/10.1215/9781478012405

Knox, H. (2021), 'Digital Devices: Knowing Material Culture', in T. Carroll, A. Walford \& S.M. Walton (eds) Lineages and Advancements in Material Culture Studies (Abingdon, Routledge). https://doi.org/10.4324/9781003085867-8

Knox, H. (forthcoming 2022), 'Technology, Environment and the Ends of Knowledge', in M.H. Bruun, D.B. Kristensen, R. Douglas-Jones, C. Hasse, K. Høyer, B.R. Winthereik \& A. Wahlberg (eds) Handbook of the Anthropology of Technology (Basingstoke, Palgrave Macmillan).

Latour, B. (1993), We Have Never Been Modern (New York, London, Prentice Hall/Harvester Wheatsheaf).

Latour, B. \& Weibel, P. (2005), Making Things Public. Atmospheres of Democracy (Cambridge, MA, MIT Press).

Lippert, I. (2015), 'Environment as Datascape: Enacting Emission Realities in Corporate Carbon Accounting', Geoforum, 66: 126-35. https://doi.org/10.1016/j.geoforum.2014.09.009

Luckin, B. (1990), Questions of Power: Electricity and Environment in Inter-war Britain (Manchester, Manchester University Press).

Lury, C. (2021), Problem Spaces: How and Why Methodology Matters (Cambridge, Polity Press). 
Marres, N. (2011), 'The Costs of Public Involvement: Everyday Devices of Carbon Accounting and the Materialization of Participation', Economy and Society, 40(4): 510-33. https://doi.org/10.1080/03085147.2011.602294

Marres, N. (2015), Material Participation: Technology, The Environment And Everyday Publics (Basingstoke, Palgrave Macmillan).

Mattern, S. (2015), 'Mission Control: A History of the Urban Dashboard', Places (March). https:// placesjournal.org/article/mission-control-a-history-of-the-urban-dashboard/?cn-reloaded=1; https://doi.org/10.22269/150309

Mora, C., Rollins, R.L., Taladay, K., Kantar, M.B., Chock, M.K., Shimada, M. \& Franklin, E.C. (2018), 'Bitcoin Emissions Alone Could Push Global Warming Above $2{ }^{\circ} \mathrm{C}$ ', Nature Climate Change, 8: 931-3. .https://doi.org/10.1038/s41558-018-0321-8

Nafus, D. (2016), Quantified: Biosensing Technologies in Everyday Life (Cambridge, MA, MIT Press). https://doi.org/10.7551/mitpress/9780262034173.001.0001

Naus, J., Bas, J. M. van Vliet \& Hendriksen, A. (2015), 'Households as Change Agents in a Dutch Smart Energy Transition: On Power, Privacy and Participation', Energy Research \& Social Science, 9: 125-36. https://doi.org/10.1016/j.erss.2015.08.025

Nolden, C., Barnes, J. \& Nicholls, J. (2020), 'Community Energy Business Model Evolution: A Review of Solar Photovoltaic Developments in England', Renewable and Sustainable Energy Reviews, 122: 109722. https://doi.org/10.1016/j.rser.2020.109722

Özden-Schilling, C. (2015), Economy Electric (Oxford, Blackwell).https://doi.org/10.14506/ca30.4.06

Özden-Schilling, C. (2016), 'The Infrastructure of Markets: From Electric Power to Electronic Data', Economic Anthropology, 3(1): 68-80. https://doi.org/10.1002/sea2.12045

Ruppert, E., Isin, E. \& Bigo, D. (2017), 'Data Politics', Big Data \& Society, 4(2): 2053951717717749. https://doi.org/10.1177/2053951717717749

Schivelbusch, W. (1988), Disenchanted Night: The Industrialisation of Light in the Nineteenth Century trans A. Davies (Oxford, Berg).

Schnitzler, A. von (2016), Democracy's Infrastructure: Techno-politics and Protest After Apartheid (Princeton, NJ, Princeton University Press). https://doi.org/10.23943/princeton/9780691170770.001.0001

Shove, E. \& Walker, G. (2014), 'What Is Energy For? Social Practice and Energy Demand', Theory, Culture and Society, 31(5): 41-58. https://doi.org/10.1177/0263276414536746

Shove, E., Walker, G. \& Brown, S. (2014), 'Material Culture, Room Temperature and the Social Organisation of Thermal Energy', Journal of Material Culture, 19(2): 113-24. https://doi.org/10.1177/1359183514525084

Strengers, Y. (2012), 'Peak Electricity Demand and Social Practice Theories: Reframing the Role of Change Agents in the Energy Sector', Energy Policy, 44: 226-34. https://doi.org/10.1016/j.enpol.2012.01.046

Zuboff, S. (2019), The Age of Surveillance Capitalism: The Fight for the Human Future at the New Frontier of Power (London, Profile Books).

To cite the article: Hannah Knox (2021), 'Making climate public: energy monitoring and smart grids as political participation ', Journal of the British Academy, 9(s9): 183-204.

DOI https://doi.org/10.5871/jba/009s9.183

Journal of the British Academy (ISSN 2052-7217) is published by The British Academy, 10-11 Carlton House Terrace, London, SW1Y 5AH www.thebritishacademy.ac.uk 